\title{
Effects of once- versus twice-a-day feeding of pasteurized milk supplemented with yeast-derived feed additives on growth and health in female dairy calves
}

\author{
D. J. Saldana, ${ }^{1}$ C. M. Jones, ${ }^{1}$ A. M. Gehman, ${ }^{2}$ and A. J. Heinrichs ${ }^{1 *}$ \\ ${ }^{1}$ Department of Animal Science, The Pennsylvania State University, University Park 16802 \\ ${ }^{2}$ Alltech Inc., Nicholasville, KY 40356
}

\section{ABSTRACT}

The objective of this study was to compare the effects of feeding preweaning dairy calves pasteurized milk once or twice a day with or without a combination of yeast-derived products. Holstein heifer calves $(\mathrm{n}=$ 48) from The Pennsylvania State University dairy herd were fed $3.8 \mathrm{~L}$ of colostrum in 1 feeding and randomly assigned to 1 of 4 treatments (once-a-day milk feeding with or without live yeast culture and mannan-rich fraction and twice-a-day milk feeding with or without live yeast culture and mannan-rich fraction). All calves were fed $6 \mathrm{~L}$ of milk daily. Weekly growth measurements and blood samples were taken $3 \mathrm{~h}$ after the morning milk feeding for all animals. Growth measurement included body weight, hip width, and withers height. Calf starter refusal was recorded weekly, and a sample was taken to determine dry matter intake. Daily health scores were recorded for each calf using a standard scoring system. Intake, growth measurements, haptoglobin, and health scores data were analyzed using repeated measures analysis with calf included as a random variable. Preweaning average daily gain was 553.4 and $512.1 \mathrm{~g} / \mathrm{d}$ for calves fed milk once and twice a day, respectively, and we found no difference between treatments. Preweaning calf starter intake was 242.3 and $198.7 \mathrm{~g} / \mathrm{d}$ for calves fed milk once and twice a day, respectively, and we found no treatment differences. Preweaning calf starter intake was 224.3 and $216.6 \mathrm{~g} / \mathrm{d}$ for calves fed yeast and without yeast, respectively. Withers height and hip width were similar in calves fed milk either once or twice a day; however, calves fed yeast tended to have greater withers height and hip width than control calves. Haptoglobin concentration as a measure of stress had least squares means of 4.0 and $9.5 \pm 3.5 \mu \mathrm{g} / \mathrm{mL}$ for calves fed milk once or twice a day, respectively, and we found no difference among treatments. Scours score and total daily score were similar for calves fed milk once or twice a day. These

Received September 14, 2018.

Accepted December 20, 2018.

*Corresponding author: ajh@psu.edu results suggest that feeding milk once a day can be successfully applied to a calf feeding system and that yeast products may improve structural growth.

Key words: feeding frequency, yeast culture, dairy calf

\section{INTRODUCTION}

In the United States $94.6 \%$ of farms feed calves milk twice a day. In contrast, $0.8 \%$ of all operations use once-a-day feeding (NAHMS, 2014). Early studies on once-a-day milk feeding showed the convenience and labor advantages of this system (Wilson, 1968; Galton and Brakel, 1976). Labor is the second largest expense in heifer rearing, accounting for $13.8 \%$ of the total cost to raise a heifer in a milking operation (Gabler et al., 2000). Feeding calves once a day could be an alternative to reduce labor expenses, because it has been shown that feeding milk once a day requires 39\% less labor than feeding twice a day (Galton and Brakel, 1976). Several studies have compared once- versus twice-a-day milk feeding systems and have not seen differences in growth measurements, rumen development (Wilson, 1968; Ackerman et al., 1969), blood constituents (Stanley et al., 2002), or health scores between systems (Kehoe et al., 2007). Interestingly, we found no published data showing any significant differences between feeding once versus twice daily. When feeding whole milk or a milk replacer containing dried whole milk, casein and milk fat form a curd in the abomasum, giving calves an opportunity to slowly digest nutrients over a long period (18 to $24 \mathrm{~h}$ ) after feeding, which allows this feeding system to be successful (Davis and Drackley, 1998). European and New Zealand companies are aggressively marketing once-a-day feeding (Ngahiwi, 2017) to reduce labor for feeding.

The latest National Animal Health Monitoring System survey (NAHMS, 2014) reported a decrease in the use of milk replacer on dairy farms from $85.9 \%$ in 2011 to $63.9 \%$ in 2014 . This decrease is largely a result of changes in the price of milk replacer ingredients and mailbox milk prices, which favor moving to whole milk and waste milk. This may represent a great opportunity to implement a once-a-day milk feeding system on farms 
where management can make the changes and take advantage of lower labor costs. When feeding whole milk or waste milk, calves may be exposed to pathogens such as Mycobacterium avium ssp. paratuberculosis (Streeter et al., 1995), Salmonella spp. (McEwen et al., 1988), Mycoplasma spp. (Walz et al., 1997), Listeria monocytogenes (Farber et al., 1988), Campylobacter spp. (Lovett et al., 1983), Mycobacterium bovis (Steele et al., 1997), and Escherichia coli (Selim and Cullor, 1997). However, these pathogens can all be reduced or eliminated by pasteurization, which is the process of heating milk to a target temperature for a certain time, resulting in a reduction of pathogens. On US farms, pasteurized milk is used to feed $7.4 \%$ of calves and $35.8 \%$ of all heifers (NAHMS, 2014); however, unpasteurized whole milk is the primary feed being used. The costs of pasteurizing whole milk are often quite small. Jones and Heinrichs (2017) estimated the cost of feeding 60 calves pasteurized whole milk to be $\$ 109.93 / \mathrm{d}$ and the cost of feeding the same animals a 20:20 milk replacer to be $\$ 114.10 /$ d; however, the cost will shift depending on milk prices and what portion of the feed is waste versus saleable milk.

Another common practice in calf rearing systems is the supplementation of additives, such as yeast culture or fractionated yeast, in the milk. Yeast culture was first used as source of vitamin B in the dairy calf diet (Eckles et al., 1924). Later studies focused on the effects of yeast on the rumen environment in young and adult animals (Erasmus et al., 1992; Yoon and Stern, 1996; Kumar et al., 1997). When calves are supplemented with yeast culture, starter intake increases, which could be attributed to stabilization of rumen $\mathrm{pH}$ due to lower lactic acid concentrations (Williams et al., 1991). Similarly, Quigley et al. (1992) reported an increase in starter intake before weaning for calves supplemented with yeast; however, intakes decreased after weaning. Improved gain and efficiency are reasons yeast is often added to the diet of older growing animals (Lascano and Heinrichs, 2007). However, we noted inconsistency in the results among studies when yeast is added to the diet, which may be partly due to different yeast inclusion rates and yeast types (Lascano and Heinrichs, 2007). Adding yeast to a calf's diet can reduce morbidity and mortality (Cole et al., 1992) and reduce scours and electrolyte and antibiotic treatments (Seymour et al., 1995). Lesmeister et al. (2004) reported an increase in growth measurements and slight improvement in rumen development parameters in yeast-supplemented calves. For this reason, the objective of our study was to compare the effects of a once- or twice-a-day milk feeding of a combination of live yeast culture (Yea Sacc; Alltech, Nicholasville, KY) and mannan-rich fraction of the yeast cell wall (Actigen; Alltech) to preweaning dairy calves as a supplement to pasteurized milk; we specifically investigated intake, BW gain, structural growth, and health.

\section{MATERIALS AND METHODS}

This research was approved by The Pennsylvania State University institutional animal care and use committee (IACUC \# 47457). Forty-eight Holstein heifer calves from The Pennsylvania State University dairy herd born between March and September 2017 were separated from their dams soon after birth and placed in a $1.0 \times 1.0 \mathrm{~m}$ holding pen until colostrum feeding. All calves were fed $3.8 \mathrm{~L}$ of heat-treated colostrum in 1 feeding within $2 \mathrm{~h}$ after birth, followed by whole milk feedings. After colostrum feeding, calves were placed in $1.2 \times 2.4 \mathrm{~m}$ individual pens bedded with straw and sawdust located inside a naturally and mechanically ventilated barn until 7 wk of age. Calves were randomly assigned to 1 of the 4 treatments: once-a-day milk feeding with or without yeast and twice-a-day milk feeding with or without yeast. All calves were fed $6 \mathrm{~L}$ of pasteurized whole milk in 2 equal feedings from $\mathrm{d} 1$ to 7. A batch pasteurizer (PLV model, 2c, Duecinox, Guastalla, Italy) was used to pasteurize the milk at $65^{\circ} \mathrm{C}$ for 30 min.

Milk samples were collected periodically and frozen at $-20^{\circ} \mathrm{C}$ for bacterial and component analysis. Calves fed milk once a day were fed $6 \mathrm{~L}$ in the morning from $\mathrm{d}$ 7 until weaning. Calves fed milk twice a day received 3 $\mathrm{L}$ in the morning and $3 \mathrm{~L}$ in the evening from $\mathrm{d} 7 \mathrm{until}$ weaning. Milk feeding amount was reduced in half in both treatments at $35 \mathrm{~d}$ of age and calves were weaned at $42 \mathrm{~d}$. Calves assigned to yeast treatment were fed $1.5 \mathrm{~g} / \mathrm{d}$ of the mannan-rich fraction (Actigen; Alltech) in the milk and offered texturized calf starter (Ridley Feeds, Lancaster, PA) containing live yeast culture (Yea-Sacc; Alltech) at $0.3 \%$ DM (targeted dose $2 \mathrm{~g} /$ head per d) ad libitum beginning at $3 \mathrm{~d}$ of age. Control calves were offered texturized calf starter without yeast culture ad libitum from $3 \mathrm{~d}$. Water was provided at libitum and replaced 2 times a day.

Milk samples were thawed at $20^{\circ} \mathrm{C}$ to measure bacterial content, as described by Jayarao et al. (2004). Milk samples were analyzed for SPC and coliform count. Milk samples were mixed and $50 \mu \mathrm{L}$ were pipetted on to the plate and spread using a sterile, L-shaped polypropylene cell spreader. All samples were cultured in duplicate for SPC using plate count agar and coliform count using MacConkey's agar. Cultures were incubated at $37^{\circ} \mathrm{C}$ for $48 \mathrm{~h}$ and then colonies were counted. Counts from duplicate plates were averaged and converted to logarithmic counts. Milk samples (Table 1) were sent to Dairy One Cooperative Inc. (Ithaca, NY) 
Table 1. Milk compositional analysis and bacteria counts before and after pasteurization $(\mathrm{n}=5)$

\begin{tabular}{lc}
\hline Item & Amount \\
\hline TS, \% & 12.8 \\
Protein, \% & 3.8 \\
Fat, \% & 3.5 \\
SPC, log cfu $/ \mathrm{mL}$ & \\
Before & 3.3 \\
After & 1.5 \\
Coliform, log cfu/mL & \\
Before & 1.5 \\
After & 0.4 \\
\hline
\end{tabular}

to be analyzed for fat, total protein, and TS using methods 989.05, 991.20, and 990.20, respectively, of AOAC International (1996).

Calf starter samples (Table 2) were sent to Cumberland Valley Analytical Services Inc. (Waynesboro, PA) to be analyzed for DM, CP, ADF, ash, and minerals (AOAC International, 2000), and NDF (Van Soest et al., 1991). Weekly growth measurements were taken $3 \mathrm{~h}$ after the morning milk feeding for all animals. Growth measurement included BW, hip width, and withers height. A jugular blood sample from each calf was collected into 10-mL serum Vacutainer tubes (Becton Dickinson, Franklin Lakes, NJ) at $24 \mathrm{~h}$ after birth to determine serum protein. Serum protein was determined using an optical refractometer (SPR-T2, Atago Co. Ltd., Tokyo, Japan) calibrated with distilled water before each use. In addition, weekly jugular blood samples were taken 3 $\mathrm{h}$ after morning milk feeding and collected into $10-\mathrm{mL}$ sodium heparin Vacutainer tubes (Becton Dickinson) for haptoglobin determination by ELISA. Samples were diluted 1:100 in the solution provided in the ELISA kit (HAPT-11; Life Diagnostics Inc., West Chester, PA); we followed the manufacturer's instructions (http:// www.lifediagnostics.com/wp-content/uploads/HAPT -11.pdf) to determine haptoglobin concentration. Calf starter refusal was recorded weekly and a sample was taken to determine DMI. Daily health scores, which focused on scours, respiration, general appearance, and total daily score, were recorded for each calf using a standard scoring system, with each category scored from 1 (normal) to 5 (abnormal; CalfTrack; Lesmeister and Heinrichs, 2004).

All results were evaluated for normality using the UNIVARIATE procedure of SAS (version 9.4; SAS Institute Inc., Cary, NC). Intake, growth measurements, and haptoglobin concentration data were analyzed using repeated measures analysis and the MIXED procedure of SAS. Yeast supplementation, times fed per day, and their interaction were included as fixed effects. Calf was included as a random variable. Birth BW and wk-1 hip width and withers height were evalu- ated as potential covariates for growth data but were removed from the final models because no differences due to these factors were found. The AR (1) covariance structure was used in the model for repeated measures of intake and growth measurements. The ARH (1) covariance structure was used in the model for haptoglobin. Health score data were converted to a binary format (score of 1 or $2=$ healthy, score $>2=$ sick) and analyzed with the GLIMMIX procedure of SAS, using the Laplace method for likelihood approximation and Morel's corrected empirical estimator for bias correction of standard errors. Newton-Raphson with ridging was specified for nonlinear optimization. Fixed effects in the model included yeast treatment, number of times fed per day, and their interaction. Day was included as a repeated effect using calf within yeast and times fed as the subject term. Logit and complementary log-log link functions were evaluated and selected based on Akaike's information criterion and Pearson chi-squareto-degrees of freedom ratio. A logit link was used for scour data and the complementary log-log for total score. Tukey's adjustment for multiple comparisons was used to compare all least squares means. Significance was declared at $P<0.05$ and trends at $P<0.10$.

\section{RESULTS AND DISCUSSION}

All calves completed the study. Serum total protein at $24 \mathrm{~h}$ averaged 6.0 for all treatments $(P=0.60)$. However, 2 calves had serum total protein values $<5.2$ $\mathrm{g} / \mathrm{dL}$, which is considered failure of passive transfer; 1 calf was from the once-a-day milk feeding without yeast treatment and the other was from the twice-a-day milk feeding without yeast treatment. Body weight least squares means are shown in Table 3 . No differences between once or twice-a-day feeding were detected $(P$ $=0.17)$, and the inclusion of a mannan-rich fraction

Table 2. Compositional analysis of calf starters $(n=5 /$ treatment $)$

\begin{tabular}{lcc}
\hline Item & Control & $\begin{array}{c}\text { Live yeast } \\
\text { culture }^{1}\end{array}$ \\
\hline $\mathrm{DM}, \%$ & 96.3 & 96.3 \\
$\mathrm{CP}, \%$ & 20.4 & 21.4 \\
$\mathrm{ADF}, \%$ & 8.6 & 9.3 \\
$\mathrm{NDF}, \%$ & 15.2 & 16.4 \\
$\mathrm{Ash}, \%$ & 9.0 & 8.6 \\
$\mathrm{Ca}, \%$ & 1.5 & 1.4 \\
$\mathrm{P}, \%$ & 0.7 & 0.7 \\
$\mathrm{Mg}, \%$ & 0.5 & 0.4 \\
$\mathrm{~K}, \%$ & 1.4 & 1.5 \\
$\mathrm{Na}, \%$ & 0.8 & 0.6 \\
$\mathrm{Fe}, \mathrm{mg} / \mathrm{kg}$ & 452 & 437 \\
$\mathrm{Mn}, \mathrm{mg} / \mathrm{kg}$ & 260 & 258 \\
$\mathrm{Zn}, \mathrm{mg} / \mathrm{kg}$ & 378 & 868 \\
$\mathrm{Cu}, \mathrm{mg} / \mathrm{kg}$ & 91 & 99 \\
\hline
\end{tabular}

${ }^{1} 0.3 \%$ of DM, $2 \mathrm{~g} /$ head per day of targeted dose rate. 
in the milk and live yeast culture in the starter did not affect $\mathrm{BW}(P=0.33)$. Preweaning ADG was 553.4 and $512.1 \mathrm{~g} / \mathrm{d}$ for calves fed milk once and twice a day, respectively; however, we found no difference between treatments $(P=0.11)$. As seen for BW, ADG was higher in calves fed milk once a day compared with calves fed milk twice a day during wk $2(P<0.01)$, as previously explained. In both treatments, ADG decreased during weaning in wk 6 . Postweaning ADG was not different among treatments $(P=0.14)$; however, overall ADG showed a tendency to be greater in calves fed milk once a day compared with calves fed milk twice a day $(P=$ 0.07). Overall ADG was 545.2 and $572.0 \mathrm{~g} / \mathrm{d}$ for calves fed a mannan-rich fraction in the milk and live yeast culture in the starter and control calves, respectively. Inclusion of a mannan-rich fraction in the milk and live yeast culture in the starter did not affect overall ADG $(P=0.39)$.

Our results are in agreement with Wilson (1968), Willett et al. (1969), and Kehoe et al. (2007), who also found no differences in preweaning ADG between calves fed milk once or twice a day. We found no published studies that reported differences between once and twice daily feeding of milk to calves. Kehoe et al. (2007) reported greater preweaning ADG in calves fed milk replacer once a day versus twice a day; however, no significant differences were reported between systems for overall ADG, as occurred in the present study. A study supplementing yeast culture at 1 and $2 \%$ of $\mathrm{DM}$ in the calf starter reported no difference between control and yeast culture-fed calves in preweaning ADG (Lesmeister et al., 2004). A similar study feeding $0.2 \%$ yeast culture in the calf starter found no difference between yeast culture-fed and control calves in pre- and postweaning ADG (Quigley et al., 1992). Both studies agree with the results reported in the present study; however, Lesmeister et al. (2004) showed a positive difference between calves supplemented with yeast culture at $2 \%$ of $\mathrm{DM}$ in the calf starter and control calves for overall ADG.

After 2 wk of age, calves fed milk once a day had a numerically higher calf starter intake compared with calves fed twice a day; however, we found no difference between treatments (Figure 1; $P=0.47$ ). Feeding calves once a day may encourage more starter intake due to the long interval between milk feedings. However, several studies have shown that feeding milk either once or twice daily does not affect starter consumption (Willett et al., 1969; Stanley et al., 2002; Kehoe et al., 2007). Kehoe et al. (2007) reported higher values for calf starter intake compared with the present study; this difference could be attributed to a feeding more volume and using whole milk rather than milk replacer in the present experiment. In the present study, preweaning (first $42 \mathrm{~d}$ of the study) calf starter intake was 242.3 and $198.7 \mathrm{~g} / \mathrm{d}$ for calves fed milk once and twice a day, respectively, but we found no treatment differences $(P=0.35)$. In addition, Willett et al. (1969) reported greater starter consumption in calves fed milk once a day compared with twice a day, but the dif-

Table 3. Least squares means of growth parameters and haptoglobin concentration for calves fed milk once or twice daily with or without yeast supplementation $(\mathrm{n}=12 /$ treatment $)$

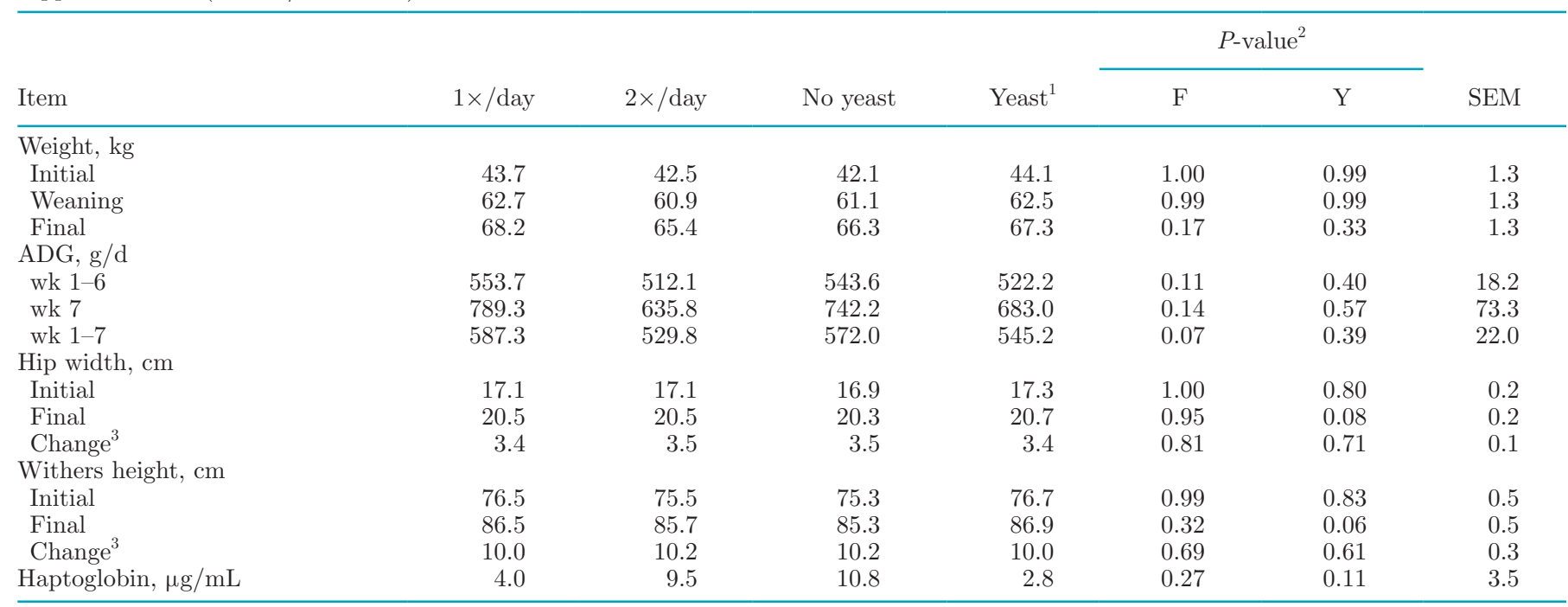

${ }^{1}$ Actigen in milk and Yea-Sacc in calf starter; Alltech, Nicholasville, KY.

${ }^{2} \mathrm{~F}=$ feeding frequency (once or twice a day); $\mathrm{Y}=$ yeast supplementation (with or without yeast). Models also included interaction between feeding frequency and yeast supplementation, which was not significant for any of the variables.

${ }^{3}$ Calculated as wk 7 - wk 1 . 
ference was not significant. As expected, calf starter intake increased after weaning in both treatments $(P$ $\leq 0.01$ ). Preweaning calf starter intake was 224.3 and $216.6 \mathrm{~g} / \mathrm{d}$ for calves fed a mannan-rich fraction in the milk and live yeast culture in the starter and control calves, respectively (Figure 2). Similar to Quigley et al. (1992) and Lesmeister et al. (2004), the inclusion of a mannan-rich fraction in the milk and live yeast culture in the starter did not affect calf starter intake $(P=$ $0.92)$.

Least squares means for structural growth measurements are reported in Table 3 . Withers height and hip width were the same in calves fed milk either once or twice a day $(P=0.32$ and 0.95 , respectively). This result agrees with Kehoe et al. (2007), who also did not report differences in withers height between calves fed milk once or twice a day. The most interesting result was observed in calves fed mannan-rich fraction in the milk and live yeast culture in the starter, where final withers height and hip width in these calves tended to be higher than control calves $(P=0.06$ and 0.08 , respectively). However, we detected no differences between treatments for change in withers height or hip width over the 7 -wk trial. Lesmeister et al. (2004) also found withers height tended to be greater in calves supplemented with yeast culture at a higher level in the starter than calves supplemented with yeast culture at a lower level as well as greater than control calves. In addition, Mir and Mir (1994) reported a numerical increase in carcass weight in steers fed yeast, suggesting that yeast has an effect on bone growth.

Haptoglobin concentration least squares means were 4.0 and $9.5 \pm 3.5 \mu \mathrm{g} / \mathrm{mL}$ for calves fed milk once or twice a day, respectively, and we found no difference among treatments $(P=0.27$; Table 3$)$. Haptoglobin concentration least squares means were 10.8 and 2.8 $\pm 3.5 \mu \mathrm{g} / \mathrm{mL}$ for calves without yeast and calves with yeast, respectively, and we found no difference among treatments $(P=0.11)$. We attributed this to the high variability in the haptoglobin data. There were 22 calfweeks where haptoglobin concentration was $>10 \mu \mathrm{g} /$ $\mathrm{mL}$, of which $14 \mathrm{wk}$ were from control calves and $8 \mathrm{wk}$ from yeast calves. Haptoglobin concentration increases after inflammatory stimuli or acute phase reactions and is used as an indicator of inflammation (Morimatsu et al., 1992; Nakajima et al., 1993). In addition, haptoglobin concentration can be used as an indicator of stressful management practices, such as transportation or feedlot entry (Araujo et al., 2010; Cooke et al., 2012). In healthy animals, haptoglobin concentration has been defined as $<350 \mu \mathrm{g} / \mathrm{mL}$ (Horadagoda et al., 1994) or $<50 \mu \mathrm{g} / \mathrm{mL}$ (Gelsinger et al., 2015), meaning the calves were clearly not sick or stressed in the present study.

Calves were very healthy overall, and we detected no differences in the incidence of scours between treatments. A total of $68 \mathrm{~d}$ with a scour score exceeding 2 were recorded, with 23 individual calves contributing to this total $(\mathrm{n}=14$ calves not fed yeast and 9 fed

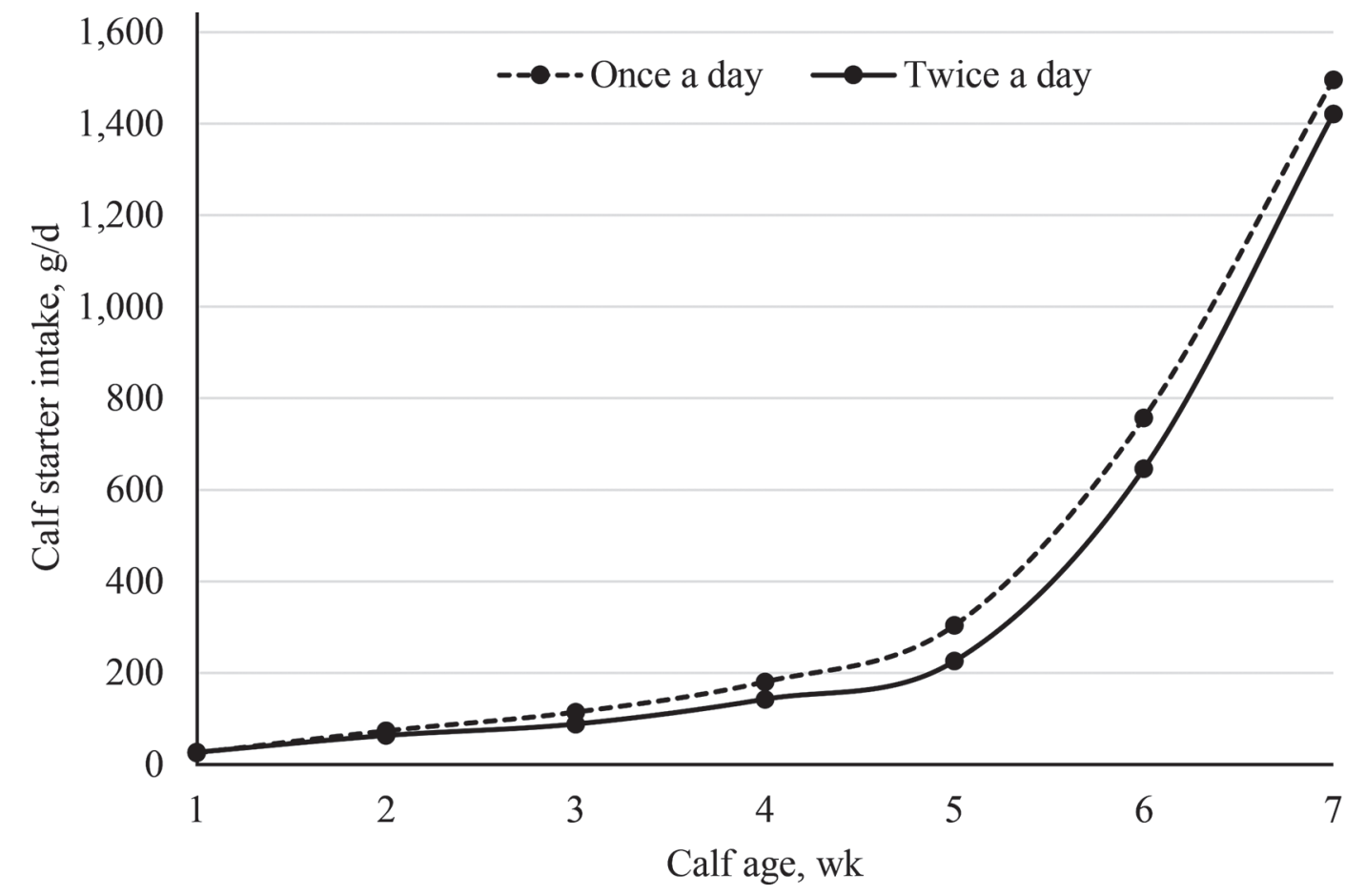

Figure 1. Calf starter intake for calves fed milk once or twice daily $(\mathrm{SEM}=47, P=0.47)$. 


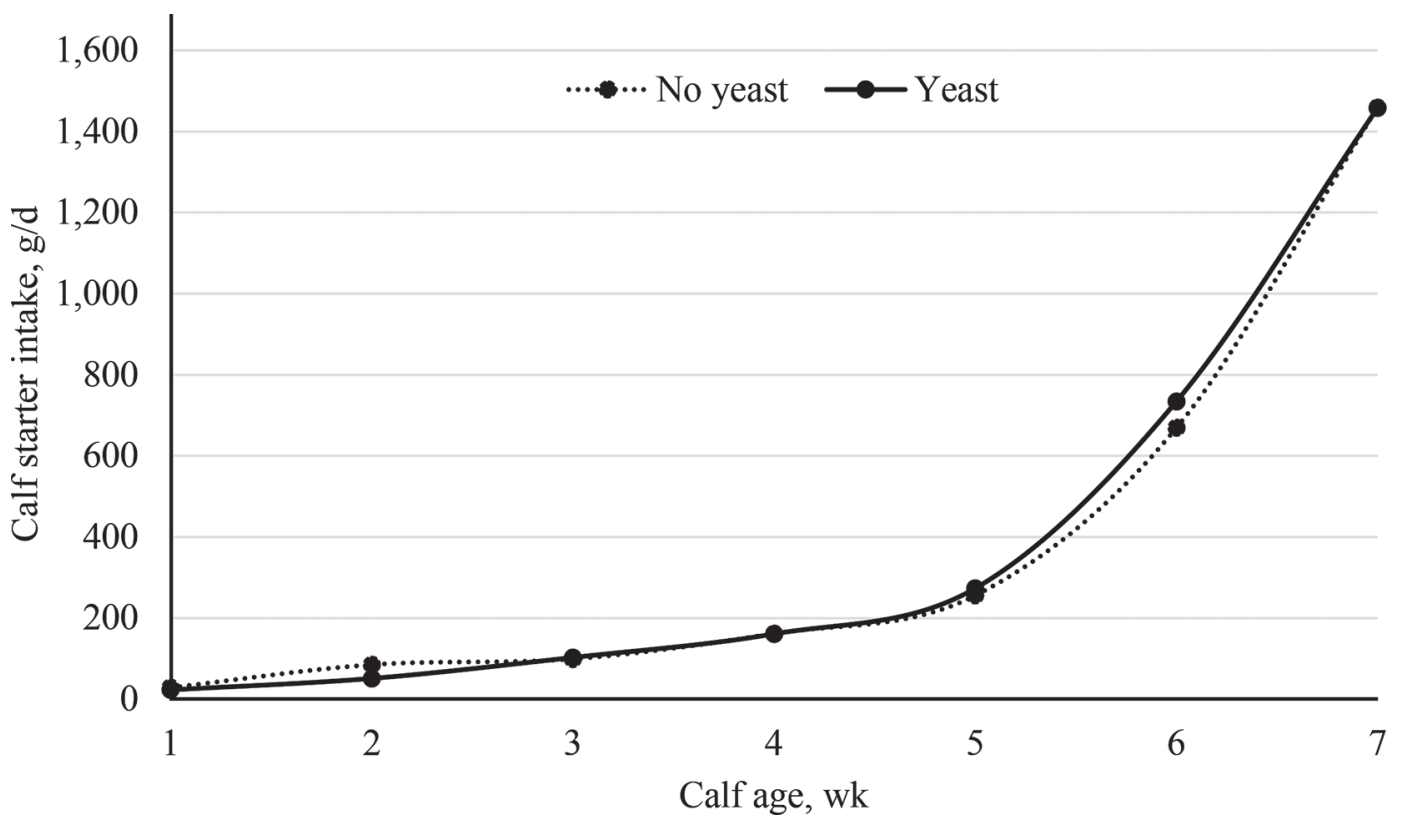

Figure 2. Calf starter intake for calves with or without yeast supplementation ( $\mathrm{SEM}=47, P=0.92)$.

yeast; 13 calves fed 1 time/d and 10 fed twice daily). Total daily scores above 2 were only recorded on $7 \mathrm{~d}$ (4 individual calves, all from the no-yeast treatment) during the trial. Due to extreme differences in the occurrence of our binary outcomes (and resulting values of infinity for treatment effects), statistical differences in total daily score could not be determined. These results support previous research that found no differences in scours, digestive disorders, or health scores of calves fed milk once or twice a day (Willett et al., 1969; Owen and Larson, 1982; Kehoe et al., 2007). Magalhães et al. (2008) reported an improvement in calf heath and reduced treated days in calves fed yeast culture at $2 \%$ of the starter DM, whereas Jensen et al. (2007) showed that soluble products present in yeast culture modulate the immune system; however, other studies have not been able to detect differences in calf health (Lesmeister et al., 2004). Inconsistent results in this respect may be due to differences in the amount of yeast supplemented, the form of the yeast products, and the many factors affecting calves' immune status and the intensity of a disease challenge.

\section{CONCLUSIONS}

Calves fed pasteurized milk once a day were not different than calves fed milk twice a day in BW, ADG, calf starter intake, growth measurements, or health scores, indicating that feeding milk once a day can be successful. The inclusion of a mannan-rich fraction in the milk and live yeast culture in the starter did not affect ADG, calf starter intake, or health scores. We noted a tendency for increased withers height and hip width in calves supplemented with a mannan-rich fraction in the milk and live yeast culture in the starter.

\section{ACKNOWLEDGMENTS}

We thank Andrea Chiesi from Duecinox, Guastalla, Italy, for providing the calf milk pasteurizer. Calf starter was supplied by Ridley Feeds (Lancaster, PA). In addition, D. J. Saldana's graduate assistantship was supported in part by Alltech Inc. (Nicholasville, KY).

\section{REFERENCES}

Ackerman, R. A., R. O. Thomas, W. V. Thayne, and D. F. Butcher. 1969. Effects of once-a-day feeding of milk replacer on body weight gain of dairy calves. J. Dairy Sci. 52:1869-1872. https://doi.org/10 .3168/jds.S0022-0302(69)86860-8.

AOAC International. 1996. Official Methods of Analysis 16th ed. AOAC Int., Gaithersburg, MD.

AOAC International. 2000. Official Methods of Analysis. 17th ed. AOAC Int., Gaithersburg, MD.

Araujo, D. B., R. F. Cooke, G. R. Hansen, C. R. Staples, and J. D. Arthington. 2010. Effects of rumen-protected polyunsaturated fatty acid supplementation on performance and physiological responses of growing cattle after transportation and feedlot entry. J. Anim. Sci. 88:4120-4132. https://doi.org/10.2527/jas.2009-2684.

Cole, N. A., C. W. Purdy, and D. P. Hutcheson. 1992. Influence of yeast culture on feeder calves and lambs. J. Anim. Sci. 70:16821690. https://doi.org/10.2527/1992.7061682x.

Cooke, R. F., J. A. Carroll, J. Dailey, B. I. Cappellozza, and D. W. Bohnert. 2012. Bovine acute-phase response after different doses of corticotropin-releasing hormone challenge. J. Anim. Sci. 90:23372344 . 
Davis, C. L., and J. K. Drackley. 1998. The Development, Nutrition, and Management of the Young Calf. Iowa State University Press, Ames.

Eckles, C. H., V. M. Williams, J. W. Wilbur, L. S. Palmer, and H. M. Harshaw. 1924. Yeast as a supplementary feed for calves. J. Dairy Sci. 7:421-439. https://doi.org/10.3168/jds.S0022-0302(24)94040 -9 .

Erasmus, L. J., P. M. Botha, and A. Kistner. 1992. Effect of yeast culture supplement on production, rumen fermentation, and duodenal nitrogen flow in dairy cows. J. Dairy Sci. 75:3056-3065.

Farber, J. M., G. W. Sanders, and S. A. Malcolm. 1988. The presence of Listeria spp. in raw milk in Ontario. Can. J. Microbiol. 34:95-100.

Gabler, M. T., P. R. Tozer, and A. J. Heinrichs. 2000. Development of a cost analysis spreadsheet for calculating the costs to raise a replacement dairy heifer. J. Dairy Sci. 83:1104-1109.

Galton, D. M., and W. J. Brakel. 1976. Influence of feeding milk replacer once versus twice daily on growth, organ measurements, and mineral content of tissues. J. Dairy Sci. 59:944-948. https:// doi.org/10.3168/jds.S0022-0302(76)84302-0.

Gelsinger, S. L., C. M. Jones, and A. J. Heinrichs. 2015. Effect of colostrum heat treatment and bacterial population on immunoglobulin $\mathrm{G}$ absorption and health of neonatal calves. J. Dairy Sci. 98:4640-4645.

Horadagoda, A., P. D. Eckersall, J. C. Hodgson, H. A. Gibbs, and G. M. Moon. 1994. Immediate responses in serum TNF $\alpha$ and acute phase protein concentrations to infection with Pasteurella haemolytica A1 in calves. Res. Vet. Sci. 57:129-132. https://doi.org/10 1016/0034-5288(94)90094-9.

Jayarao, B. M., S. R. Pillai, A. A. Sawant, D. R. Wolfgang, and N. V. Hegde. 2004. Guidelines for monitoring bulk tank milk somatic cell and bacterial counts. J. Dairy Sci. 87:3561-3573.

Jensen, G. S., A. N. Hart, and A. G. Schauss. 2007. An antiinflammatory immunogen from yeast culture induces activation and alters chemokine receptor expression on human natural killer cells and B lymphocytes in vitro. Nutr. Res. 27:327-335. https://doi.org/10 $.1016 /$ j.nutres.2007.04.008

Jones, C. M., and A. J. Heinrichs. 2017. Cost comparison of various calf feeding programs. Accessed May 15, 2018. https://extension .psu.edu/cost-comparison-of-various-calf-feeding-programs.

Kehoe, S. I., C. D. Dechow, and A. J. Heinrichs. 2007. Effects of weaning age and milk feeding frequency on dairy calf growth, health and rumen parameters. Livest. Sci. 110:267-272. https://doi.org/ 10.1016/j.livsci.2006.11.007.

Kumar, U., V. K. Sareen, and S. Singh. 1997. Effect of yeast culture supplement on ruminal microbial populations and metabolism in buffalo calves fed a high roughage diet. J. Sci. Food Agric. 73:231-236. https://doi.org/10.1002/(SICI)1097-0010(199702)73: $2<231$ :AID-JSFA710>3.0.CO;2-D.

Lascano, G. J., and A. J. Heinrichs. 2007. Yeast culture (Saccharomyces cerevisiae) supplementation in growing animals in the dairy industry. CAB Rev. Perspect. Agric. Vet. Sci. Nutr. Nat. Resour. 2:13. https://doi.org/10.1079/PAVSNNR20072049.

Lesmeister, K. E., and A. J. Heinrichs. 2004. Effects of corn processing on growth characteristics, rumen development, and rumen parameters in neonatal dairy calves. J. Dairy Sci. 87:3439-3450. https:// doi.org/10.3168/jds.S0022-0302(04)73479-7.

Lesmeister, K. E., A. J. Heinrichs, and M. T. Gabler. 2004. Effects of supplemental yeast (Saccharomyces cerevisiae) culture on rumen development, growth characteristics, and blood parameters in neonatal dairy calves. J. Dairy Sci. 87:1832-1839. https://doi.org/10 .3168/jds.S0022-0302(04)73340-8.

Lovett, J., D. W. Francis, and J. M. Hunt. 1983. Isolation of Campylobacter jejuni from raw milk. Appl. Environ. Microbiol. 46:459-462.

Magalhães, V. J. A., F. Susca, F. S. Lima, A. F. Branco, I. Yoon, and J. E. P. Santos. 2008. Effect of feeding yeast culture on performance, health, and immunocompetence of dairy calves. J. Dairy Sci. 91:1497-1509. https://doi.org/10.3168/jds.2007-0582.

McEwen, S. A., S. W. Martin, R. C. Clarke, and S. E. Tamblyn. 1988. A prevalence survey of Salmonella in raw milk in Ontario, 1986-87. J. Food Prot. 51:963-965.
Mir, Z., and P. S. Mir. 1994. Effect of the addition of live yeast (Saccharomyces cerevisiae) on growth and carcass quality of steers fed high-forage or high-grain diets and on feed digestibility and in situ degradability. J. Anim. Sci. 72:537-545.

Morimatsu, M., M. Sarikaputi, B. Syuto, M. Saito, S. Yamamoto, and M. Naiki. 1992. Bovine haptoglobin: Single radial immunodiffusion assay of its polymeric forms and dramatic rise in acute-phase sera. Vet. Immunol. Immunopathol. 33:365-372. https://doi.org/ 10.1016/0165-2427(92)90007-D

Nakajima, Y., E. Momotani, T. Murakami, Y. Ishikawa, M. Morimatsu, M. Saito, H. Suzuki, and K. Yasukawa. 1993. Induction of acute phase protein by recombinant human interleukin-6 (IL-6) in calves. Vet. Immunol. Immunopathol. 35:385-391. https://doi .org/10.1016/0165-2427(93)90047-8.

National Animal Health Monitoring System. 2014. Dairy Cattle Management Practices in the United States. USDA:APHIS, Fort Collins, CO.

Ngahiwi. 2017. The science of once-a-day calf feeding. Accessed May 2, 2018. http://ngahiwifarms.co.nz/cms/calf-rearing/the-science -of-once-a-day-calf-feeding.html.

Owen, F. G., and L. L. Larson. 1982. A simplified liquid feeding program for calves. J. Dairy Sci. 65:1350-1356. https://doi.org/10 .3168/jds.S0022-0302(82)82352-7.

Quigley, J. D., III, L. B. Wallis, H. H. Dowlen, and R. N. Heitmann. 1992. Sodium bicarbonate and yeast culture effects on ruminal fermentation, growth, and intake in dairy calves. J. Dairy Sci. 75:3531-3538. https://doi.org/10.3168/jds.S0022-0302(92)78129 -6 .

Selim, S. A., and J. S. Cullor. 1997. Number of viable bacteria and presumptive antibiotic residues in milk fed to calves on commercial dairies. J. Am. Vet. Med. Assoc. 211:1029-1035.

Seymour, W. M., J. E. Nocek, and J. Siciliano-Jones. 1995. Effects of a colostrum substitute and of dietary brewer's yeast on the health and performance of dairy calves. J. Dairy Sci. 78:412-420. https:/ /doi.org/10.3168/jds.S0022-0302(95)76650-4.

Stanley, C. C., C. C. Williams, B. F. Jenny, J. M. Fernandez, H. G. Bateman II, W. A. Nipper, J. C. Lovejoy, D. T. Gantt, and G. E. Goodier. 2002. Effects of feeding milk replacer once versus twice daily on glucose metabolism in Holstein and Jersey calves. J. Dairy Sci. 85:2335-2343. https://doi.org/10.3168/jds.S0022 -0302(02)74313-0.

Steele, M. L., W. B. McNab, C. Poppe, M. W. Griffiths, S. Chen, S A. DeGrandis, L. C. Fruhner, C. A. Larkin, J. A. Lynch, and J. A. Odumeru. 1997. Survey of Ontario bulk tank raw milk for foodborne pathogens. J. Food Prot. 60:1341-1346.

Streeter, R. N., G. F. Hoffsis, S. Bech-Nielsen, W. P. Shulaw, and D. M. Rings. 1995. Isolation of Mycobacterium paratuberculosis from colostrum and milk of subclinically infected cows. Am. J. Vet. Res. 56:1322-1324.

Van Soest, P. J., J. B. Robertson, and B. A. Lewis. 1991. Methods for dietary fiber, neutral detergent fiber, and nonstarch polysaccharides in relation to animal nutrition. J. Dairy Sci. 74:3583-3597.

Walz, P. H., T. P. Mullaney, J. A. Render, R. D. Walker, T. Mosser, and J. C. Baker. 1997. Otitis media in preweaned Holstein dairy calves in Michigan due to Mycoplasma bovis. J. Vet. Diagn. Invest. 9:250-254

Willett, L. B., J. L. Albright, and M. D. Cunningham. 1969. Onceversus twice-daily feeding of milk replacer to calves. J. Dairy Sci. 52:390-391. https://doi.org/10.3168/jds.S0022-0302(69)86566-5.

Williams, P. E., C. A. Tait, G. M. Innes, and C. J. Newbold. 1991. Effects of the inclusion of yeast culture (Saccharomyces cerevisiae plus growth medium) in the diet of dairy cows on milk yield and forage degradation and fermentation patterns in the rumen of steers. J. Anim. Sci. 69:3016-3026. https://doi.org/10.2527/1991 $6973016 \mathrm{x}$

Wilson, J. 1968. Once-daily feeding of calves. Vet. Rec. 83:42-43.

Yoon, I. K., and M. D. Stern. 1996. Effects of Saccharomyces cerevisiae and Aspergillus oryzae cultures on ruminal fermentation in dairy cows. J. Dairy Sci. 79:411-417. 